Abdelmegid MA., Gonzalez VA., O’Sullivan M., Walker CG., Poshdar M., and Alarcon, LF. (2019). "Establishing A Link Between the Last Planner System and Simulation: A Conceptual Framework." In: Proc. $27^{\text {th }}$ Annual Conference of the International. Group for Lean Construction (IGLC), Pasquire C. and Hamzeh F.R. (ed.), Dublin, Ireland, pp. 335-346 DOI: https://doi.org/10.24928/2019/0200. Available at: <www.iglc.net>.

\title{
ESTABLISHING A LINK BETWEEN THE LAST PLANNER SYSTEM AND SIMULATION: A CONCEPTUAL FRAMEWORK
}

\author{
Mohammed A. Abdelmegid ${ }^{1}$, Vicente A. González², Michael O'Sullivan³ ${ }^{3}$, Cameron \\ G. Walker ${ }^{4}$, Mani Poshdar ${ }^{5}$, Luis Fernando Alarcón 6
}

\begin{abstract}
The Last Planner System (LPS) is considered one of the most established lean-based construction planning methods due to its ability to stabilise construction production and to increase plan reliability. Several technologies have been proposed to support the implementation of the LPS such as simulation modelling, BIM, and spreadsheets. Simulation modelling is proven to support construction project management by providing a virtual means to test decisions before real implementation. This study aims at establishing a link between the LPS and simulation modelling to support the implementation of the LPS in the construction industry. The scope of this study is focused on the Conceptual Modelling (CM) phase of simulation studies. CM encompasses the planning process of how a simulation model should be developed and how it relates back to the real system. The intended link is established by matching the elements of the LPS with simulation CM to develop an integrated LPS/CM framework. A case study of a stadium expansion project, in which the LPS was fully implemented, is presented to illustrate the applicability of the integrated framework.
\end{abstract}

\section{KEYWORDS}

Lean construction, last planner system, collaboration, simulation, conceptual modelling, first-run studies.

$1 \quad$ Ph.D. Candidate, Department of Civil and Environmental Engineering, The University of Auckland, New Zealand (Corresponding author), +64 9373 7999, E-mail: mabd556@aucklanduni.ac.nz

2 Senior Lecturer, Department of Civil and Environmental Engineering, The University of Auckland, Auckland 1142, New Zealand, +64 9923 4106, E-mail: v.gonzalez@ auckland.ac.nz

3 Senior Lecturer, Department of Engineering Science, The University of Auckland, Auckland, New Zealand, +649923 7907, E-mail: michael.osullivan@auckland.ac.nz

4 Associate Professor, Department of Engineering Science, The University of Auckland, Auckland, New Zealand, +64 9923 7009, E-mail: cameron.walker@auckland.ac.nz

5 Lecturer, Department of Built Environment Engineering, Auckland University of Technology, Auckland 1142, New Zealand, +64 921 9999, E-mail: mani.poshdar@aut.ac.nz

6 Professor, Department of Construction Engineering and Management, Pontificia Universidad Catolica de Chile, Santiago, Chile. E-mail: lalarcon@ing.puc.cl 


\section{INTRODUCTION}

Computer simulation modelling has proven to be a potent decision-support tool for construction project management (Martinez 2010). Extensive research has been ongoing to utilise simulation modelling to solve complex construction management problems for more than four decades. However, there is a consensus in the construction research community that simulation modelling suffers from a lack of large-scale adoption within the industry (Leite et al. 2016). Among the reasons identified are the need to invest considerable time and effort to develop simulation models and the lack of technical simulation training among construction practitioners (Leite et al. 2016). Based on the observation by Bernold (1987), introducing new technologies to the construction industry requires integrating the technologies with the traditional methods of construction. Therefore, this study is motivated by the effort to address the gap of lack of simulation adoption in the construction industry through the integration of computer simulation with current practices of construction management.

CM incorporates the planning phase of simulation studies as it provides a softwareindependent description of the simulation model (Robinson 2014). Van der Zee (2012) concluded that aligning $\mathrm{CM}$ with engineering management environment can help in integrating simulation modelling into engineering practices. Thus, CM can be integrated with construction planning to initiate a link between simulation and construction. The LPS was selected for the integration as it is a well-established construction planning methodology which has gained popularity within the industry due to its ability to stabilise construction production and to increase plan reliability (González et al. 2008). The LPS and CM share commonalities in several fundamental aspects that motivated the integration. First, the granularity of information in both methods follows a hierarchical way to breakdown the plan from a high-level abstract representation of the project to a detailed operation design. Second, the fact that the LPS implementation structure is composed of a number of steps at different planning levels makes the integration to $\mathrm{CM}$ a feasible avenue of development for the LPS in the construction simulation domain, representing another opportunity for improving production planning and control in construction projects. Third, the LPS and CM include collaborative activities that encourage the engagement of stakeholders to promote transparency and trust building (Hamzeh et al. 2015; Van der Zee 2012). Another motivation for the integration is the proven benefits of CM in stimulating creativity (Kotiadis et al. 2014), which matches the group creativity techniques required to implement several activities in the LPS (Daniel 2017).

The implementation of the LPS requires a detailed design of operations (Ballard et al. 2007). First-run studies (FRS), sometimes referred to as prototyping (Daniel 2017), is suggested as an approach to support operations design by providing a better understanding of the construction process before the real implementation on site (Daniel 2017). FRS must be executed in as realistic a way as possible to test operations, learn how to perform them best, identify requirements, understand their interactions with other processes, and capture best practices (Ballard et al. 2007). FRS is performed physically or virtually, and they usually take place during the lookahead planning stage (Hamzeh et al. 2015). Based on the description of FRS, it is clear that there is an excellent opportunity to exploit the advanced 
capabilities of computer simulation to assist in virtually conducting FRS. However, there is a scarce of research on the use of computer simulation to conduct virtual FRS. In general, FRS received minimal interest in LPS-related research (Daniel et al. 2015). Therefore, this paper proposes the use of an integrated framework to assist in building simulation models, to support conducting virtual FRS during the LPS implementation.

\section{LITERATURE REVIEW}

\section{THE USE OF SIMULATION MODELLING IN LEAN CONSTRUCTION RESEARCH}

Simulation modelling has been heavily employed by the lean construction community to evaluate the effectiveness of lean construction measures in improving project performance. It has been proven that simulation modelling offers an excellent tool to virtually implement lean construction principles, quantify their impact, and demonstrate their applications (AlSudairi et al. 1999; Farrar et al. 2004; Mao and Zhang 2008). Moreover, several studies provided good examples of using Discrete Event Simulation (DES) in lean-based production system design methods (Halpin and Kueckmann 2002; Schramm et al. 2008; Tommelein 1998). These studies provided DES models to test the effect of different production system design choices on project performance indicators such as buffer size, project duration, and productivity measures. However, the scope of these studies did not include a methodology to integrate the practices of lean-based production system design methods and simulation modelling.

\section{THE USE OF SIMULATION MODELLING IN THE LPS}

Several studies used simulation modelling to demonstrate the concepts of the LPS and to improve its processes. For instance, Hamzeh et al. (2015) applied DES to study the effect of improving the ability of construction teams to properly anticipate tasks during the lookahead planning phase of the LPS on the overall project duration. Faloughi et al. (2014) used DES to test a prototype for a visual information software platform (SimpLean), which aims at enabling construction companies to implement the basic elements of the LPS. Moreover, System Dynamics (SD) was employed by Mota et al. (2010) to help understand the behaviour of the LPS performance indicators by testing the effect of variability and delays on project performance. In conclusion, simulation modelling has been mostly utilised in the LPS literature as a support tool to test research hypotheses and to improve understanding of the LPS.

Xie (2011) asserted that an interesting relationship can be identified between the LPS and simulation modelling. However, his observation was only limited to short term planning and project control aspects of the LPS by matching the elements of weekly work plans with DES models. González et al. (2013) introduced a simulation-based methodology to design and manage buffer in construction projects at three planning levels (which are very similar to the LPS planning levels): strategic, tactical, and operational. Even though the study provided an excellent example on the integration of construction planning with simulation modelling, the objective of the proposed framework was limited to designing and managing buffer in repetitive construction projects without explicitly linking the planning activities with the practices of simulation modelling. 


\section{RESEARCH METHOD}

Due to the practical nature of the implementation of the LPS, case study approach has been the prominent research method in LPS-related literature (Daniel et al. 2015). However, the use of proactive research methods such as design science research has been favoured in lean construction research (Daniel et al. 2015; Koskela 2008). Design science research can be defined as a research method in which a researcher addresses a specific problem by creating an innovative artefact, which contributes new knowledge to the body of research (Koskela 2008). It employs a stepwise approach to build an artefact then assess its contribution and utility (Koskela 2008). Therefore, this paper follows the steps of the design science research method as defined by Kasanen et al. (1993) (see Figure 1).

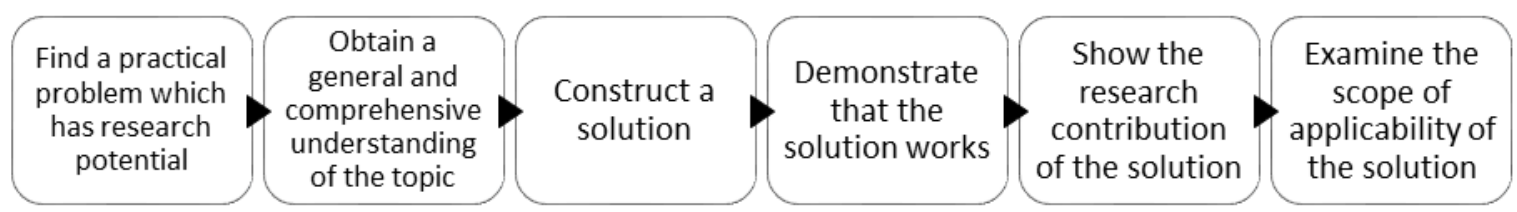

Figure 1: Design science research (Kasanen et al. 1993)

The first and second steps of the design science research method have been accomplished in the introduction and literature review sections of this paper. An integrated framework is developed to embody the innovative solution in the third step of the design science research method. A case study of a construction project, in which the LPS was fully implemented, is conducted to demonstrate the utility of the solution based on the fourth step of the research method. The conclusion of this paper explains the research contribution and future research directions to examine the scope of applicability of the integrated framework.

\section{THE INTEGRATED LPS/CM FRAMEWORK}

In order to initiate a link between the LPS and computer simulation, integration of the data/information and the processes of the LPS and CM was completed based on the recommendations of Van der Zee (2012) for systems integration. In order to perform the integration, the LPS was analysed to identify its detailed processes and information generated during implementation. The description of the LPS in Ballard et al. (2007) and Hamzeh et al. (2015) was utilised to aid the analysis. On the other hand, the CM framework for construction simulation proposed by Abdelmegid et al. (2017) was used to guide the integration. This framework is based on other CM frameworks in the operations research literature with several alterations to suit the unique nature of construction systems. The left side of Figure 2 shows the LPS stages and the generated information through different stages, while the right side illustrates the processes and flow of information for the CM framework. Visualising the LPS and CM side by side helped in revealing the link between them by identifying the similarities in processes and information. As depicted in Figure 2Figure 2, the CM framework pulls all the required information from different stages in the LPS to build the model. Then, solutions are fed back to the LPS through the implemented computer model. However, in some cases, solutions for the problems in hand 
can spark during the $\mathrm{CM}$ process thus diminishing the need to proceed with the full computer modelling study (Robinson 2014).

It is important to point out that the directions of the arrows in the CM framework are to show the sequence of the steps. However, with the advancement of the processes of CM, improved understanding of the system can be obtained which may require adjustments to the deliverables of previous steps (Robinson 2014). Additionally, the implementation of the LPS may vary depending on the size and type of construction projects (Ballard et al. 2007). Therefore, the application of the proposed framework should be flexible to adapt to any variation from the original design.

\section{CASE STUDY}

The integrated LPS/CM framework has been applied in a case study of a construction project to expand and renovate a multi-use public stadium in Chile. The project duration is 382 days and is estimated to cost USD 11,350,000. It consists of several multi-storey buildings for seating terraces, shops, warehouses, gates, ticket offices and public bathrooms in addition to an expansion of the surrounding landscaping and parking areas. The LPS was fully implemented to plan and control the project with detailed documentation of each level. The project included several construction activities such as demolition, earthwork, reinforced concrete construction, steel structure erection, and finishing. The scope of the case study was limited to the reinforced concrete operations for building foundations, columns, and walls. The following is a discussion of the steps of the integrated framework accompanied by examples from the conceptual model that was developed for the case study.

\section{SIMULATION STUDY INITIATION}

As a formal start to the simulation study, a proposal should be developed to include a description of the simulation team, a preliminary timeline, data requirements, and the involvement effort required from the construction company. This step aims at managing clients' expectations by justifying the feasibility of the simulation study. The master plan of the LPS can assist the modeller to initiate the simulation study by providing stakeholders' information, project constraints, and timeline.

\section{Problem formulation}

The first deliverable of this step is a formal representation of the problem under consideration. Additionally, the modeller might need to make some assumptions due to the lack of information at this stage. These assumptions should be updated during the life cycle of the study to incorporate new information at each step.

By analysing the problems listed in the LPS documentations of the case study, it was found that delays in reinforced concrete operations were repeatedly reported due to the lack of labour and materials, poor coordination between resources, and bad weather. Moreover, reinforced concrete activities were scattered between 11 site locations. Therefore, the main problem identified for this case study was the need for effective coordination and optimised allocation of resources to avoid delays and disruptions. 


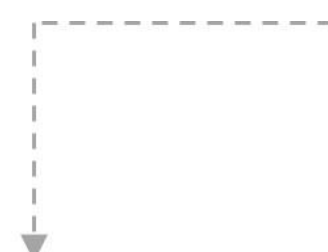

\section{Conceptual Modelling (CM)}

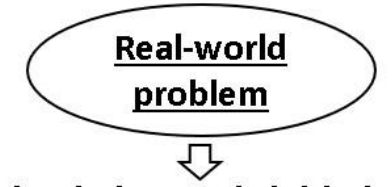

The Last Planner System (LPS)

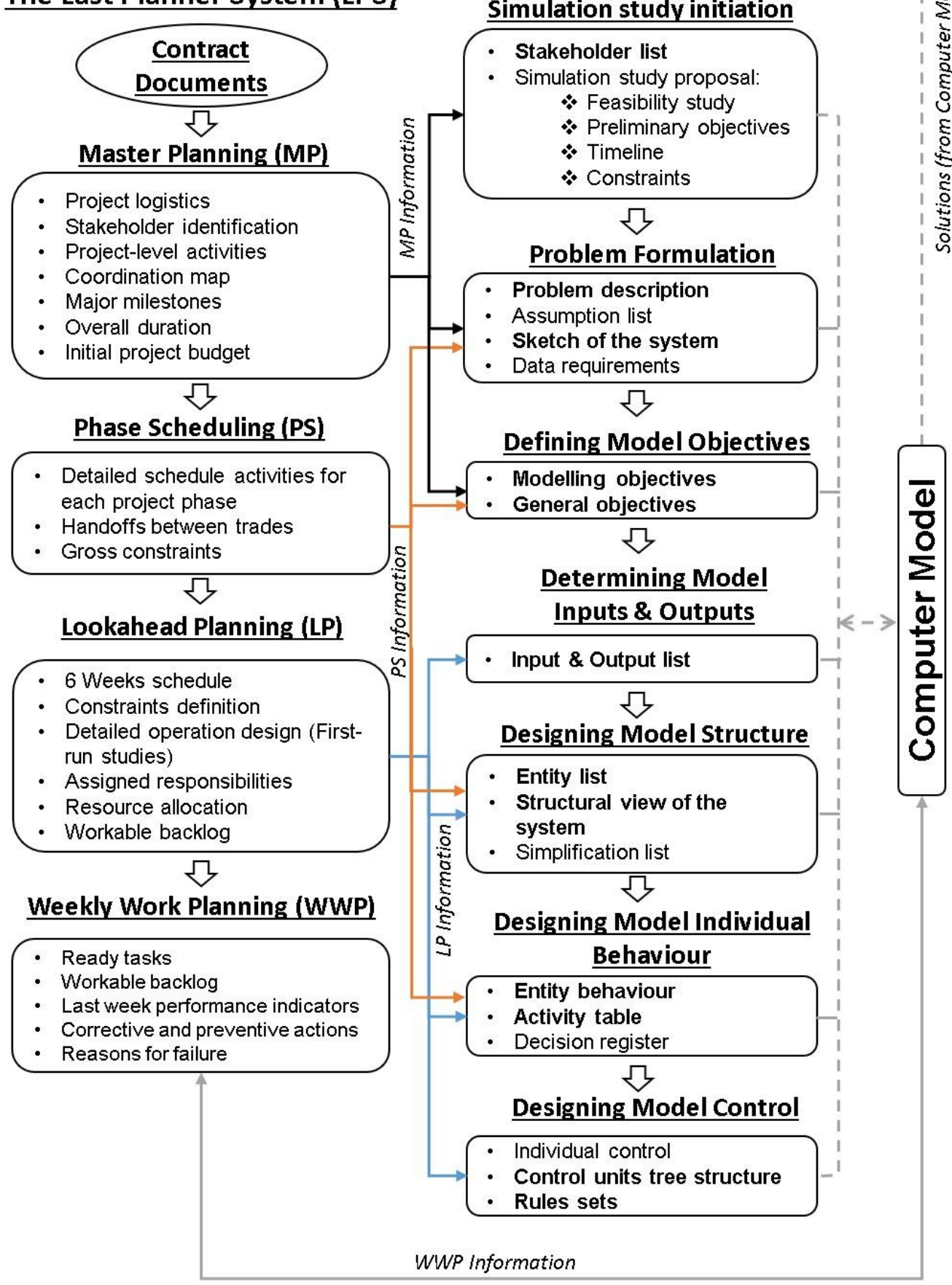

Figure 2: The integrated LPS/CM framework 


\section{DEFINING MODEL OBJECTIVES}

The integrated framework defines objectives in two categories: general objectives and modelling objectives (Robinson 2014). The modeller can use the information in the master plan of the LPS to define general objectives such as timeline and model flexibility. The definition of modelling objectives extends the problem formulation from the last step. These objectives can be defined collaboratively during the phase scheduling stage of the LPS. Table 1 summarises all the modelling and general objectives of the case study.

Table 1: Model objectives

\begin{tabular}{cc}
\hline & General Objectives \\
\hline $\begin{array}{c}\text { Study duration } \\
\text { Visualisation }\end{array}$ & A simple site layout that shows site sectors and flow of materials and crews \\
$\begin{array}{c}\text { Flexibility and } \\
\text { Reusability }\end{array}$ & The model should be flexible to allow for the addition of live information \\
during weekly work planning
\end{tabular}

\section{Modelling objectives}

Calculate total execution time of reinforced concrete operations for different sets of scenarios Calculate productivity and idle time of reinforced concrete crews

\section{DETERMINING MODEL INPUTS AND OUTPUTS}

This step requires a deep understanding of the system. In the LPS context, a detailed operation design takes place during the lookahead planning. Therefore, determining model inputs and outputs is best integrated with the lookahead planning stage.

In the case study, the inputs were set to be the sequence of sectors for concrete operations and the number of crews for each reinforced concrete trade. The outputs were set to be the total time for each scenario to find the most effective job sequence and the productivity and idle times for construction crews to assess the design of operations.

\section{DESIGNING MODEL STRUCTURE}

At this step, model entities and their relationships are identified. In the integrated framework, the modeller can utilise the information available in the resource allocation in the LPS to identify the entities and their relationships. Table 2 lists the entities of the case study. Figure 3 depicts the structural view of the case study. Crews and materials are the active entities that flow through the system. Site sectors, labour area, and storage area are passive localised entities.

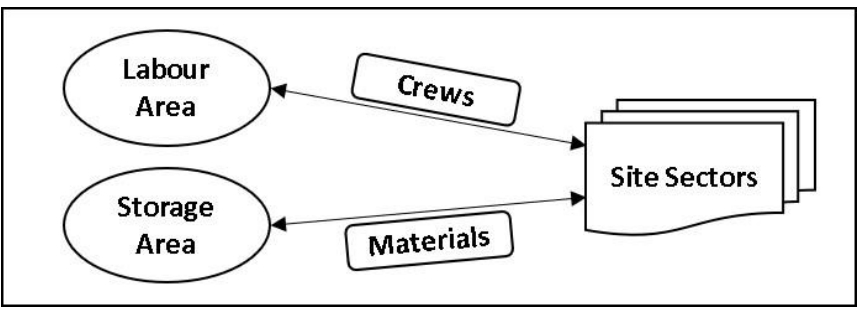

Figure 3: Structural view of the system 
Table 2: Entity list

\begin{tabular}{|c|c|c|}
\hline Entity & Type & Attributes \\
\hline Crews (Excavation, Rebaring, Formwork, Concrete) & Active & Number, Productivity \\
\hline Materials (Reinforcement Steel, Formwork, Concrete) & Active & $\begin{array}{c}\text { Quantity for each sector } \\
\text { Arrival rate }\end{array}$ \\
\hline Site sectors & Passive & Area, Location \\
\hline Storage area & Passive & Location, Capacity \\
\hline Labour area & Passive & Location, Capacity \\
\hline
\end{tabular}

\section{DESIGNING MODEL INDIVIDUAL BEHAVIOUR}

At this step, active entities are individually analysed to define their activities. We recommend the use of a Business Process Model and Notation (BPMN) diagrams as they are able to represent the location of each activity, which fits the dynamic nature of construction systems. Figure 4 shows an example of the individual behaviour of the Excavation crew. Another deliverable for this step is a list of all activities recorded in the BPMN. These activities are analysed to define their attributes, participating entities, start and end types, state changes, and control units (which will be described in the next step).

Information to design entities individual behaviour can be extracted from the detailed activity schedule during the phase scheduling, with the aid of system observation if needed. Table 3 lists the activities of the reinforced concrete operations in the case study.

\section{DESIGNING MODEL CONTROL}

The last step of the framework is to define the behaviour of the system. This step is performed by analysing the control units in the BPMN diagrams. Two deliverables are produced by this step: (1) A tree structure representing the hierarchy of control units (Figure 5), and (2) Logical flow diagrams to represent governing rules of control units (Figure 6). Responsibilities and handoffs between trades, which are determined during the lookahead window of the LPS, can be used to identify control units and assign their responsibilities. Additionally, information can be extracted from the operation design in the LPS to develop logical flow diagrams for the conceptual model.

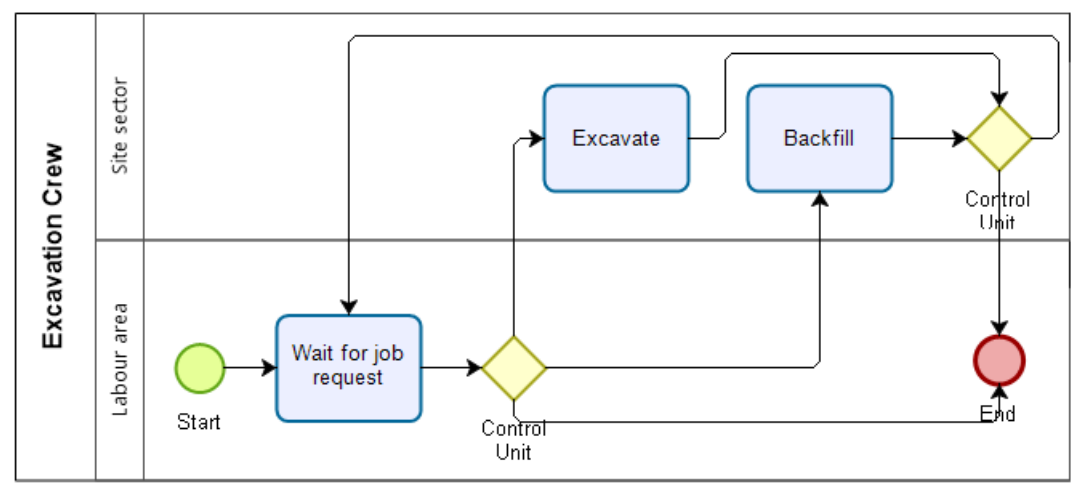

Figure 4: Individual behaviour of Excavation crew 


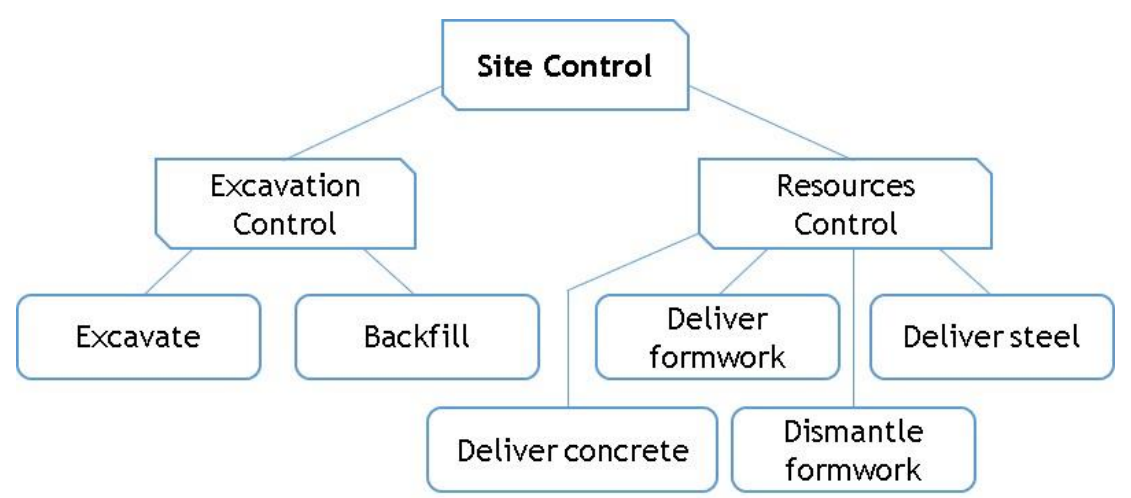

Figure 5: Control units of the case study

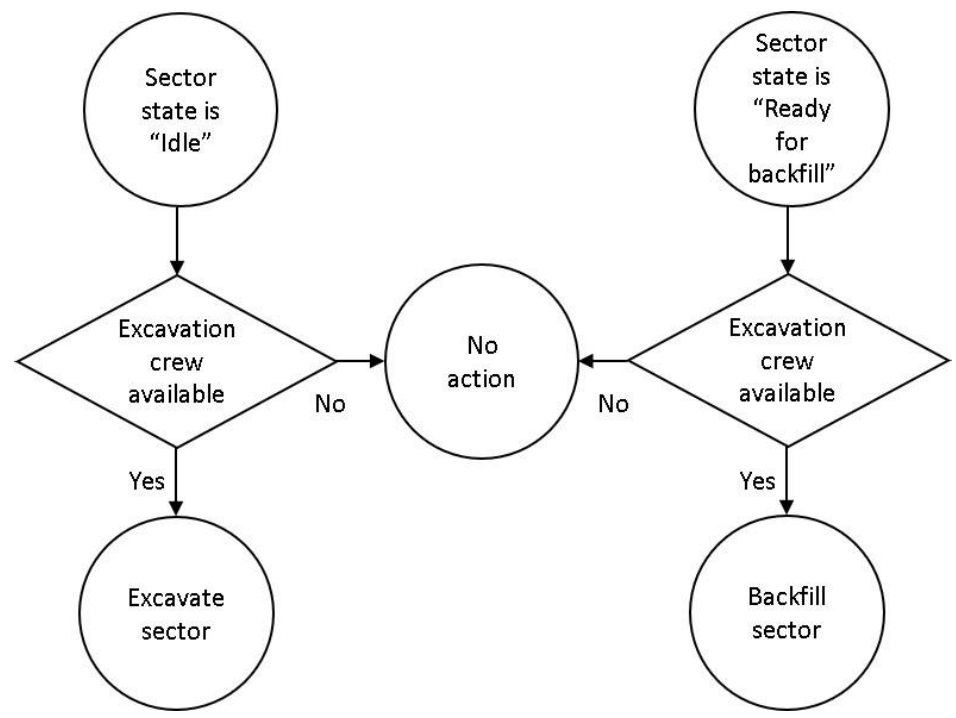

Figure 6: Control policies for the excavation control unit

\section{SUMMARY OF THE CASE STUDY}

It can be concluded that most of the information needed to build a conceptual model was available in the documentation of the LPS. As illustrated in Figure 2, the master plan was most useful for the first three steps of the CM framework. The phase schedule and lookahead plan provided technical information for the later advanced CM steps. Moreover, it was found that information in the weekly work plans was not useful for the conceptual model as such information is focused on monitoring project performance. However, weekly plans can provide information to update and validate the computer model based on live data from the site. Moreover, the design of the model may be altered, depending on the nature of operations in the weekly plans, to allow for more flexibility especially in repetitive environments (i.e. work as a template for the construction operation).

\section{CONCLUSION}

This paper examines the applicability of an integrated framework to link the LPS and simulation modelling by a real-life case study. The integrated framework utilises the 
synergy between the LPS and a simulation CM framework. It exploits the information available in the LPS to develop a simulation conceptual model. Daniel et al. (2015) asserted that the LPS has been evolving through its integration with other systems. Therefore, this paper contributes to LPS research by providing an integrated framework that can improve the LPS performance and adherence by assisting in building virtual decision-support tools through simulation modelling. Moreover, the framework aims at avoiding effort duplication by utilising available information to build the model rather than building it from scratch. Therefore, it contributes to the body of knowledge in construction simulation research by providing a means to enable rapid building of simulation models.

This study has potential limitations. The integrated framework was applied retrospectively on the case study, and the resulted model was not used in the real project. Future work should investigate the ability to utilise the integrated framework to conduct a complete simulation study side by side while the LPS is being implemented.

Table 3: Activity list of the case study

\begin{tabular}{|c|c|c|c|c|c|}
\hline No. & Activity & Entities & Start Type & End Type & Control Unit \\
\hline 1 & Excavate sector & $\begin{array}{c}\text { Excavation crew } \\
\text { Site sectors }\end{array}$ & Requested & Scheduled & $\begin{array}{l}\text { Excavation } \\
\text { control }\end{array}$ \\
\hline 2 & $\begin{array}{l}\text { Deliver formwork } \\
\text { to sector }\end{array}$ & $\begin{array}{l}\text { Storage area } \\
\text { Site sectors }\end{array}$ & Requested & Scheduled & $\begin{array}{l}\text { Resources } \\
\text { control }\end{array}$ \\
\hline 3 & $\begin{array}{l}\text { Formwork } \\
\text { erection }\end{array}$ & $\begin{array}{l}\text { Formwork crew } \\
\text { Site sectors }\end{array}$ & Sequential & Scheduled & $N . A$. \\
\hline 4 & $\begin{array}{l}\text { Deliver steel to } \\
\text { sector }\end{array}$ & $\begin{array}{l}\text { Storage area } \\
\text { Site sectors }\end{array}$ & Requested & Scheduled & $\begin{array}{l}\text { Resources } \\
\text { control }\end{array}$ \\
\hline 5 & Rebaring & $\begin{array}{l}\text { Rebaring crew } \\
\text { Site sectors }\end{array}$ & Sequential & Scheduled & $N . A$. \\
\hline 6 & $\begin{array}{l}\text { Deliver concrete } \\
\text { to sector }\end{array}$ & $\begin{array}{l}\text { Storage area } \\
\text { Site sectors }\end{array}$ & Requested & Scheduled & $\begin{array}{l}\text { Resources } \\
\text { control }\end{array}$ \\
\hline 7 & Concrete pour & $\begin{array}{l}\text { Concrete, Formwork \& } \\
\text { Rebaring crew } \\
\text { Site sectors }\end{array}$ & Sequential & Scheduled & $N . A$. \\
\hline 8 & $\begin{array}{l}\text { Dismantle } \\
\text { formwork }\end{array}$ & $\begin{array}{l}\text { Concrete crew } \\
\text { Site sectors }\end{array}$ & Requested & Scheduled & $\begin{array}{l}\text { Resources } \\
\text { control }\end{array}$ \\
\hline 9 & $\begin{array}{l}\text { Send formwork } \\
\text { back to storage }\end{array}$ & $\begin{array}{l}\text { Storage area } \\
\text { Site sectors }\end{array}$ & Sequential & Scheduled & N.A. \\
\hline 10 & Backfill sector & $\begin{array}{c}\text { Excavation crew } \\
\text { Site sectors }\end{array}$ & Requested & Scheduled & $\begin{array}{l}\text { Excavation } \\
\text { control }\end{array}$ \\
\hline
\end{tabular}




\section{REFERENCES}

Abdelmegid, M. A., Gonzalez, V. A., O'Sullivan, M., Walker, C. G., Poshdar, M., and Naraghi, A. M. "Towards A Conceptual Modeling Framework for Construction Simulation." Proc., 2017 Winter Simulations Conference (WSC) 2372-2383.

Al-Sudairi, A. A., Diekmann, J. E., Songer, A. D., and Brown, H. M. (1999). "Simulation of construction processes: Traditional practices versus lean principles." USA: University of California, 39-50.

Ballard, G., Hamzeh, F., and Tommelein, I. (2007). The Last Planner Production Workbook-Improving Reliability in Planning and Workflow.

Bernold, L. E. (1987). "Automation and robotics in construction: a challenge and a chance for an industry in transition." International Journal of Project Management, 5(3), 155-160.

Daniel, E. I. (2017). "Exploratory study into the use of Last Planner® System and collaborative planning for construction process improvement." Nottingham Trent University.

Daniel, E. I., Pasquire, C., and Dickens, G. (2015). "Exploring the implementation of the Last Planner® System through IGLC community: twenty one years of experience."

Faloughi, M., Bechara, W., Chamoun, J., and Hamzeh, F. "Simplean: An effective tool for optimizing construction workflow." Proc., 22nd Annual Conference of the International Group for Lean Construction, 281-292.

Farrar, J. M., AbouRizk, S. M., and Mao, X. (2004). "Generic implementation of lean concepts in simulation models." Lean Construction Journal, 1(1), 1-23.

Furian, N., O’Sullivan, M., Walker, C., Vössner, S., and Neubacher, D. (2015). "A conceptual modeling framework for discrete event simulation using hierarchical control structures." Simulation Modelling Practice and Theory, 56, 82-96.

González, V., Alarcón, L. F., and Mundaca, F. (2008). "Investigating the relationship between planning reliability and project performance." Production Planning and Control, 19(5), 461-474.

González, V., Alarcón, L. F., and Yiu, T. W. J. J. o. t. O. R. S. (2013). "Integrated methodology to design and manage work-in-process buffers in repetitive building projects." 64(8), 1182-1193.

Halpin, D. W., and Kueckmann, M. "Lean construction and simulation." Proc., Winter Simulation Conference Proceedings, 1697-1703.

Hamzeh, F. R., Saab, I., Tommelein, I. D., and Ballard, G. (2015). "Understanding the role of "tasks anticipated" in lookahead planning through simulation." Automation in Construction, 49, Part A, 18-26.

Kasanen, E., Lukka, K., and Siitonen, A. (1993). "The constructive approach in management accounting research." Journal of management accounting research, 5(1), 243-264.

Koskela, L. (2008). "Which kind of science is construction management?" 16th Annual Conference of the International Group for Lean Construction, The University of Salford, Manchester, UK, 51-60. 
Kotiadis, K., Tako, A. A., and Vasilakis, C. (2014). "A participative and facilitative conceptual modelling framework for discrete event simulation studies in healthcare." Journal of the Operational Research Society, 65(2), 197-213.

Leite, F., Cho, Y., Behzadan, A., Lee, S., Choe, S., Fang, Y., Akhavian, R., and Hwang, S. (2016). "Visualization, Information Modeling, and Simulation: Grand Challenges in the Construction Industry." Journal of Computing in Civil Engineering, 30(6), 04016035.

Mao, X., and Zhang, X. (2008). "Construction process reengineering by integrating lean principles and computer simulation techniques." Journal of Construction Engineering and Management, 134(5), 371-381.

Martinez, J. C. (2010). "Methodology for Conducting Discrete-Event Simulation Studies in Construction Engineering and Management." Journal of Construction Engineering and Management, 136(1), 3-16.

Mota, B. P., Viana, D. D., and Isatto, E. L. "Simulating the last planner with systems dynamic." Proc., 18th Annual Conference of International Group for Lean Construction (IGLC-18), Haifa, Israel.

Robinson, S. (2014). Simulation : the practice of model development and use, Houndmills, Basingstoke, Hampshire ; New York, NY : Palgrave Macmillan. 2014.

Schramm, F., L. Silveira, G., Paez, H., Mesa, H., Formoso, C., and Echeverry, D. (2008). Using discrete-event simulation for the support of decision-makers in production system design and operation.

Tommelein, I. D. (1998). "Pull-driven scheduling for pipe-spool installation: Simulation of lean construction technique." Journal of Construction Engineering and Management, 124(4), 279-288.

Van der Zee, D. J. "An integrated conceptual modeling framework for simulation - Linking simulation modeling to the systems engineering process." Proc., Simulation Conference (WSC), Proceedings of the 2012 Winter, 1-12.

Xie, H. (2011). "Improving Dynamic Project Control in Tunnel Construction." NR89561 Ph.D., University of Alberta (Canada), Ann Arbor. 